\title{
Transmuting Gender Binaries: the Theoretical Challenge
}

\author{
by Surya Monro \\ Leeds Metropolitan University
}

Sociological Research Online, Volume 12, Issue 1, < http://www.socresonline.org.uk/12/1/monro.htm/> doi:10.5153/sro. 1514

Received: 25 Jan 2006 Accepted: 30 Jan 2007 Published: 31 Jan 2007

\begin{abstract}
This paper provides a cross-cultural account of gender diversity which explores the territory that is opened up when sex, gender, and sexual orientation, binaries are disrupted or displaced. Whilst many people who identify as trans or intersex see themselves as male or female, others identify in ways which destabilize sex/gender and sexual orientation binaries. The paper provides a typology of ways in which sex/gender diversity can be conceptualized, and draws out the implications for theorizing gender. It discusses the contributions made by the new wave of authors working in the field of transgender studies; authors who draw on and inform the sociology of sex and gender, feminisms, and poststructuralist theory. It based on empirical material from research carried out in India and the UK.
\end{abstract}

\section{Keywords: Transgender, Intersex, Gender, Diversity, Theory, Poststructuralism, Transsexuality, Sexual Orientation, Sexuality}

\section{Introduction}

We are a movement of masculine females and feminine males, cross-dressers, transsexual men and women, intersexuals born on the anatomical sweep between female and male, gender-blenders, many other sex and gender-variant people, and our significant others... Our lives are proof that sex and gender are much more complex than a delivery room doctor's glance at genitals can determine (Feinberg 1998: 5)

1.1 People whose sex/gender ${ }^{[1]}$ identity is fluid, or other than male and female, challenge the ontological assumption that sex/gender fall into binary categories. Current Western sexual orientation categories: heterosexual, lesbian, gay and bisexual, are also disrupted because they rely on sex/gender binaried forms of identity classification. The inclusion of sex/gender diverse people in discussions about gender theory problematises existing Western approaches, including feminisms, masculinity studies, and queer theory ${ }^{[2]}$. These bodies of theory often address the destabilisation of the gender binary system by people who transgress sex/gender stereotypes, but they also refer back to, and potentially reinscribe, binary systems of categorisation. Poststructuralist accounts, which deconstruct unitary notions of gender, are also flawed in some ways with respect to gender diversity. There is a long tradition of Indian theorising regarding sex, gender and sexual orientation, but this is not integrated into Western thinking.

1.2 Western trans and intersex activist engagement with poststructuralism, and/or with concepts relating to the deconstruction of sex/gender binaries, has mushroomed in recent years, including accounts by Feinberg (1996, 1998), Bornstein (1994, 1998), Wilchins (1997), Prosser (1998), More and Whittle (1999), Chase (1998) and Halberstam (2002). More recently, Western feminists and sociologists who draw on poststructuralism, such as Monro (2000a, b, 2005a, b, forthcoming), Hird (2000, 2002, 2006), and Hines (2006), have begun to explore the implications of affirmative trans and intersex identities for gender theory. Indian authors such as Vanita and Kidwai (2000) are providing analysis of sex, gender, and sexuality that integrate poststructuralist and Indian philosophy in diversity-affirmative ways, potentially informing Western thinking.

1.3 This paper aims to explore the territory that is opened up when gender, and sexual orientation, binaries are disrupted or displaced. It presents empirical data from India and the UK in order to support the argument that certain trans and intersex identities disrupt sex, gender, and sexual orientation binaries. The data has been collected over the last ten years, providing a temporal dimension to the analysis. I outline the 
ways in which the new wave of theorists have addressed trans and intersex, before building on some of the theoretical work that has been done in this field. The paper uses an inclusive definition of 'trans'

(transgender). Trans in its broadest definition can be taken to mean anyone who transgresses usual gender roles (see Raymond 1994), but it is taken here to mean cross-dressers, transsexuals, androgynes, drag kings and queens, and other gender-complex people. The term 'intersex' is sometimes included under the trans umbrella but I separate it from trans in this paper to indicate the different identities and experiences that intersex people have. I use the following definitions in the paper, whilst recognising that these are intertwined, constructed and contested: 'sex' to mean the biological (genetic, chromosomal, physiological) characteristics associated with males, females, or other bodily forms; 'gender' to mean the social identities associated with bodies that are perceived to be sexed in particular ways; 'sexuality' as desire and eroticism; and 'sexual orientation' as concerning the direction in which sexuality is projected (i.e. towards which categories of sexed/gendered persons). I acknowledge the biological aspects of sexed/gendered identities without assuming biological determinism, arguing for a combination of factors in the construction of identity. The term 'biology' is used in relation to human bodies because of the focus of the paper; discussion of the wide range of phenomena which have a biological aspect is beyond the scope of the paper.

1.4 Diversity is of importance across the trans and intersex communities, and it is important to point out that many trans and intersex people identify as male or female and would not necessarily relate to the gender pluralist theories I outline below. Also, the analysis of disability and gender/sexual fluidity and multiplicity is a pertinent issue for gender theory, which I do not deal with here (see for example Blackburn 2002). I also do not address some of the other relevant issues, such as challenges to gender norms amongst non trans people, which are widely discussed in the feminist and masculinities literature.

1.5 The paper begins by providing an outline of the methodology used for the research projects on which the paper is based. It then presents a cross-cultural comparison using data concerning sex/gender diversity gathered the UK and India. The paper then provides a brief review of recent relevant advances within the field of gender theory in relation, in particular, to poststructuralism and the biological turn. I then outline my theoretical work in relation to current developments, and develop a conceptual framework which draws out some of the implications of sex/ gender diversity for thinking about gender more generally. Whilst the theoretical work draws on the Indian material, there is certainly scope for extending this more that has been possible in a limited space.

\section{Methodology}

2.1 The bulk of my data has been drawn from three qualitative studies. The initial study was conducted between 1996 and 1998 in the UK. The design was purposive; it aimed to find contributors who were activists and/or who through their identities destabilised sex and gender binaries. However, it was also participative in that it was designed and implemented in collaboration with trans activists, the analysis was developed with trans participants as far as was possible within the confines of a doctoral project, and I also participated in trans activism. The sample included transsexuals, intersex people, cross dressers, drag kings and queens and others (a total of 24 contributed in depth interviews). Access was achieved through social contacts and via organisations such as GEMS and Press For Change, using a snowball approach. Attempts were made to gain representation across socio-economic class, age, geographical location, sexual orientation, and ethnic group. Class, age, sexual orientation, ability and geographical location differences were quite well represented, but I could only find one minority ethnic contributor, and the sample as a whole was somewhat of an elite one because I was focusing on activists who played key roles in community organisations or in the production of gender-related cultural capital. Interviews were taped and the transcriptions were checked with contributors. I also took part in over 1500 hours of participant observation over the 1996-2006 period with a broad range of trans and intersex people, and participant observation in the bisexual and fetish communities at intervals over the 1998-2006 period. A more detailed discussion of aspects of the methodology can be found in Monro (2000a).

2.2 The second, small, study of gender and sexual diversity in India, which I conducted in 2003, involved semi-structured interviews with ten sex/gender-diverse people, some conducted via a group interview. I also did a review of the coverage of gender diversity in Indian journalistic and other literature. The sample for the fieldwork was purposive and did not attempt to be representative - further work, especially concerning sex/gender-different people born as female or intersex, is needed. Most contributors identified as Kothi - a category which could be defined by Westerners as gay trans people. Interviewees were accessed via a sexual health organisation in New Delhi. The third study, which was also conducted in 2003, aimed to update the original project and to include a broader range of contributors, in particular bisexuals, who were engaged in activism concerning sexuality and gender. I conducted semi-structured interviews with 14 people accessed via organisations such as the LGB Consortium and BiCon bisexual conference. Due to time constraints the interviews for the two smaller studies were not transcribed, but material that was quoted 
was checked with contributors. Although some contributors in the second two studies could be classed as elite, many were not.

2.3 The second study was conducted as a means of enhancing the original project and the resulting data. The history of gender variance in India is particularly pertinent because of the way in which the existence people of third and other sexes and genders has been documented over a long period of time, and the extent to which people with these identities are an accepted, if stigmatised, part of Indian society. Material from this study was chosen for a paper on theorising sex/gender binaries in order to provide a cross-cultural comparison and to attempt to avoid Eurocentrism. To some degree the paper answers Roen's (2001) important critique of the ethnocentrism of much trans theorising, which draws on empirical work in New Zealand - although for a fuller cross-cultural comparison, material from other countries, for example Herdt (1994), Masequesmay (2003), Boellstorff (2004) and Blackburn (2005) would need to be utilised.

2.4 In keeping with the usual norms (see Kirsch 2000), I shall identify myself at this stage as a female bodied bisexual, who does not identify as trans in any substantial way at present, but who has explored some trans identities in the past. In all of the studies interviewees were guaranteed anonymity, with the option of being named where this was a preference. All of the quotes in the discussion of gender diversity in the UK are from the 1996-8 study unless otherwise noted. The quotes in the section on Indian gender diversity are from the 2003 research in India.

\section{Challenging Gender Binaries: A cross-cultural comparison}

3.1 Trans, Hijra, intersex and other gender-diverse people provide a fundamental ontological challenge to the sex/gender binaried system. Whilst the majority of these people exist within a gender binary system, identifying as either male or female or as both at different times, there are a range of other people who identify in sex/gender diverse ways. I shall outline these forms of gender diversity here, by looking, firstly, at the Indian situation, and, secondly, at gender and sexual diversity in the UK.

\section{Sexual and gender diversity in India}

3.2 Sex and gender variance in India has ancient, even prehistoric, roots. It is impossible to do justice to the richness and complexity that is present concerning the history of gender variance in India, but I will provide a brief overview. According to one text, 'The Hijra communities in India have a recorded history of more than 4000 years' (PUCL-K 2003: 17). Hijras, who are born as intersex or as male (some undergo castration), currently form a third sex/gender community in India, tracing their origins to the myths in the ancient Hindu scriptures of the Ramayana and Mahabarata. There is a strong faith element to Indian conceptualisations of gender, sex and sexuality. Some forms of gender variance are sanctioned via established traditions and formal rituals, and Hindu and Buddhist beliefs in reincarnation and in karma shape the way in which gender variance is perceived (Penrose 2001), for instance: 'In the Hindus view, the status of hijra is working out a particular svadharma, the spiritual life task of the individual who is travelling on the path to moksha, final release from the cycles of human existence' (2001:7).

3.3 Historically, Hijras belonged to the 'Eunuch' culture that was common across the Middle East and India, where Eunuchs worked as guards, advisors, and entertainers (PUCL-K 2003). Other forms of sex/gender pluralism in ancient India were also socially accepted. Sex/gender variant women took roles as mercenaries, advisors, and religious people, and same sex sexual expression is also documented, often taking place alongside opposite sex relationships (see Penrose 2001); 'traditionally, sexuality has always been more fluid, less rigidly categorised [than in the West]. Western naming, for many Indians, does not correspond to the amorphous nature of sexual experience' (Seabrook 1997). With the advent of British colonialism, the established social position of sex/gender variant people was systematically undermined, for example the British removed the land rights of the Hijra communities. Indigenous sexualities were also suppressed by the British (Seabrook 1997).

3.4 The empirical data gathered in New Delhi indicated that there are different systems of gender and sexuality classification operating simultaneously, set against the backdrop of ancient systems of sex/gender variance, dominant patriarchal norms, and post colonialism. These systems are being integrated to some extent by the growing LGBT communities, which bridge indigenous and western systems of categorisation, and are reportedly inclusive of Hijras and Kothis. According to contributors, gender or sexually variant Indians who are born female have fewer options than those born as male. They can identify as lesbian or transsexual, but these possibilities are often only available to the middle and upper classes. In theory, people born as male, on the other hand, can identify as gay, transgender, cross dresser, Kothi or Hijra. Intersex people are likely to become Hijras, either through choice, or because of rejection by their families. In practice, identity choices are heavily structured by caste/class and location. As Seabrook (1997) says, 'there are men who call themselves gay in India, but they are overwhelmingly middle class, English speaking, and privileged.' According to Seabrook (1997), the undefined same sex 
expression that was present prior to British rule still takes place to an extent in the slums and villages, whilst amongst the less affluent urban dwellers, a heavily gendered system of male classification has emerged. Men who have sex with men are divided into two categories - the 'karte hain' (those who do) and the 'karvate hain' (those who are done to).

3.5 The empirical material indicated that there seems to be some overlap and conflation of the categories that are assumed in the West, for instance:

Kothis belong to a community of gays - I define 'gay' as being a woman in a man's body. I want to have sex with a man as if I was a woman. I want a vagina in my body, instead of having a penis. How can I satisfy myself? Kothis want to look like girls, like Hijras do, but Kothis are those who have a penis- Hijras don't have a penis (Kothi contributor)

A Kothi has a penis and is a woman in a man's body - he wants to look like a woman and have sex with a real [sic] man (Second Kothi contributor)

3.6 Same sex sexual expression is not necessarily linked with gay identification, and that heterosexual identification is usual amongst the giriyas, or active partners. For instance, one Kothi contributor told me that 'some heterosexual men like anal sex. If I do sex with a straight man, fucking him, he gets some pleasure from anal sex. Homosexuality is about attraction, it's not physical. Kothis are further subdivided into feminine and masculine Kothis, reflecting the sex/gender binaried nature of Indian society.

3.7 There were variations in the way that contributors distinguished between Kothis, Hijras, transsexuals and transgender people. For example:

Hijras are akwas (not castrated) and nirvana (castrated) -some Hijras are akwas, so biologically they are men - they are mostly homosexual though they may be married with kids, but this is due to convenience, they are not bisexual. These are the Kothis, who cross over into the Hijra communities. Less than 1\% are intersex and $5 \%$ have been castrated ...they would not speak about this to most people because it is not in their interest (Sexual Health Organisation worker)

There is no complete separation between the Hijra and Kothi communities. Sometimes they live together, sometimes the Kothis live in the Hijra community so that they do not totally have to depend on sex work and sometimes they go dancing and when there is the birth of a child they get money. Sometimes a Kothi joins the Hijra community and does like the Hijra community (Kothi contributor).

3.8 I asked the Kothi contributors whether Kothis are different from transsexuals. One Kothi said that they are different because 'a Kothi is a man who has a women's heart, who thinks like a female'. However, another said that 'my feeling is that transsexuals and Kothis feel the same, but, the transsexual is castrated and the Kothi is not. Kothis have a difference of sex organs - I have a penis but I can satisfy another heterosexual man - but he can't satisfy me because I don't have a natural sex organ'. A further Kothi contributor said that 'transsexuals are those who have made a change in their sexuality by surgery an artificial vagina'. Contributors varied concerning their use of the terms transgender. Some did not relate to or use the term but others said for instance that 'Transgender is a term without social stigma. That is why I use it, and 'transgender and Kothi are the same'. There was not much discussion concerning intersex, but a larger sample could provide more material on this.

3.9 One of the key themes to emerge from the Indian research was the importance of socio-economic factors to the lived experience of Indian sex/gender-diverse people. The literature indicates that most Hijras belong to the poorer castes and classes, and economic marginalisation structures their experiences very heavily. As Gupta says, 'Hijras might have an accepted place in Indian society, but it is a place pretty much at the bottom of the heap - making them not only a sexual but also a highly deprived social minority' (2002:21). The contributors discussed the difficulties that Kothis and Hijras face, including having to remain closeted with families due to heavy levels of stigmatisation, abuse, and economic marginalisation. For instance one person said that:

It is very difficult for Kothis to find other work [than begging and sex work] because they don't want to be exposed. They are forced to go to the police station and because they don't want to be exposed Kothis give the police money. Also the police make money from the Kothis by taking bribes but they are not satisfied by this and they also want to have sex with the Kothis. They force it. Kothis say that every policeman is a bisexual. This situation is common, especially for sex workers - it is an everyday problem. Hijras get less trouble from the police. 
3.10 Contributors also discussed difficulties with accessing surgery for sex changes. For example one person said that 'Hijras earn a lot of money doing marriages. Sometimes I think that if I change sex I'll look like a girl and the bloke I like will want me. But people who have the operation don't have a real vagina, if you go to a good place for the operation you will get a vagina that looks like the real thing but you won't get the enjoyment unless you have expensive surgery'. Another pointed out that getting a sex change in India is very risky, due to medical difficulties and cost.

3.11 Findings also indicated that structuring factors such as faith and tradition benefited certain Indian sex/gender variant people. One contributor pointed out that Hijras occupy a position in society that is simultaneously revered and stigmatised, and that they cultivate the mystique associated with this. They are seen as having the power to curse or bless people, due to their spiritual heritage, and they are also seen as having a huge potential for embarrassment because they threaten to expose themselves physically if they are not paid for attending events such as weddings. The Hijras utilise these sources of power, retaining a somewhat secure position in society. This means that they can beg, and are less harassed by the police than other sex/gender and sexual minorities. A review of the journalistic coverage of gender diversity also showed that there are some designated political seats for Hijras. Hijra involvement in party politics is well documented in the newspapers, and Hijras are using their third sex status to advantage, marketing themselves as 'incorruptible Eunuchs' (Chakraborty 2002). As one contributor said, 'they are seen as not being part of the mainstream, which then allows them to have a place in the mainstream'.

3.12 Overall, therefore, it appeared that three main types of gender and sexual classification are current in India - unclassified sexual activity, the Hijra and Kothi systems (where what would in the West be terms transgender and same sex expression are merged, and are heavily structured by the sex/gender binary system), and Western systems. These three forms of categorisation illustrate intersectionality because their operation is a product of caste, class, and colonialism related inequalities, as well as the gender and sexuality inequalities that permeate Indian society. The Hijras, by occupying a social position in opposition to the binary system, have carved out a social space in which mainstream norms are rejected or revised, perhaps challenging, but not escaping, other structuring factors. Overall, findings problematise notions of a foundational sex/gender binary system, although there also seems to be a propensity for sex/gender binaries to be reinscribed within sex/gender minority communities.

\title{
Sexual and gender diversity in the UK
}

3.13 Documented sex/gender diversity in the UK is a much more recent phenomena than that in India (partly of course because Western civilisation as a whole is much newer). There is limited established social space or acceptance of such diversity, apart from certain traditional roles within the entertainment industry. Empirical material collected in the UK during the 1996-8 and 2003 research projects demonstrates a variety of ways in which Western sex/gender and sexual orientation binaries can be disrupted by people with trans and intersex identities. Some of the research contributors identified as other than male or female. For example, Simon Dessloch, a FTM trans person, said that he felt himself to be in-between, or neither, or both, or third sex. Similarly, Christie Elan Cane, who started life as female, said in 1998:

\begin{abstract}
I don't feel male or female, and I say that I'm basically third gender because I can't identify as male or female...I mean I'm still trying to unravel how I wanted to be, I wondered whether maybe I could be part of both, which is not how I feel any longer but I sort of went through several stages along, trying to express and figure out how I felt, but now I feel I'm neither. I can't relate to male and female.
\end{abstract}

3.14 Sex/gender binaries are sometimes disrupted by sex/gender fluidity. For example contributor Zach Nataf described the way that, during the early stages of his transition from female to male, he felt more like a man on some days and more transgendered on others, and that this depended to an extent on who he was with (see also Bornstein 1994). Butch dyke Hamish described gender fluidity as a state in itself, whilst gender transient Pheadra Kelly said:

It's about a discipline of duality with an open mind, without changing sex with hormones, with pills, with injections or surgery, living ones dualism as much as possible. If I am Phaedra, I allow elements of Bruce through, and there is no self hating or loathing going on. If I am Bruce I allow elements of Phaedra - it's horses for courses, but like the transvestite, and to some degree the trans person living full time, I live with a separate identity. I have accepted my separate identity as well.

3.15 Transsexuality can in some cases be seen as a space beyond sex/gender binarisms. Cameron (1996) frames transsexuality as an inbetween place outside of gender duality, while Stone argues that 'a trans person currently occupies a position which is nowhere, which is outside of the binaried oppositions of 
gendered discourse' (1991: 295). This was mirrored by some contributors, for example Christie Elan Cane discussed moving beyond the gender system and being non gendered. 'Gender fuck' also disrupts gender binaries. 'Gender fuck' refers to conflicting sex/gender signals - in some cases these are consciously taken on as part of identity (see Halberstam 2002). Kate N' Ha Ysabet explained that:

\begin{abstract}
...if I have a penis and big tits that's gender fuck, if I wore makeup and butch clothing that's gender fuck. And what's quite interesting is that androgyny is acceptable because there's a reason for that, but gender fuck isn't, because people go 'oh, OK'but with gender fuck its this thing of 'shit, I'm getting two sets of signals' and it feels like you're having a drum and bass mix on one side and classical music on the other and you're going 'Oh my God which am I going to listen to?'
\end{abstract}

3.16 The Western system of sexual orientation categorisation is also problematised by sex/gender diversity (see Rothblatt 1995), physically, in terms of sexual expression, and socially, in terms of identity. Whilst the majority of people can relate to notions of same sex or opposite sex attraction, the categories of LGB (lesbian, gay, and bisexual) and heterosexual are insufficient in describing, for example, attraction between an androgyne and someone who identifies as gender transient. Sexual orientation categories based on the sex/gender binary system are disrupted by physical sex diversity. The genitals of some sex/gender diverse people are physiologically 'other' than those usually associated with women and men (although, of course, they may identify as male or female). For example at the 1998 Transgender Film Festival Del LaGrace Volcano (an initially female bodied person who took testosterone) displayed photographs of his and other people's phalloclits, which resemble small penises enwreathed in labial lips. Sex between people with non standard genitals is unlikely to fit heterosexual, gay, or lesbian sexual norms. As FTM trans person James Green told me:

First of all I never had sex as a woman, and I will never have sex as a man. You know, I will always in that sense be other. And I cannot pretend that I'm not a transgender male.

3.17 Sexual orientation can be constructed in non-binary forms. For example, Queen and Schimel (1997) discuss the notion of 'omnisexual', (attracted to multiple sexes/genders), and the term 'pansexual' was coined by Firestone (1970) to mean diverse, unbounded desire. Other alternatives include for instance 'trannie lover'. These terms are not that widely used, even in the sexual fringes where people are conversant with sexual orientation fluidity. Individuals and groups continue to an extent to use existing definitions, even when they do not fit very well. For example, Annie Cox, a MTF trans person defined herself as a 'woman who loved woman' although she has a penis. Issues concerning challenges to traditional sexual orientation categories also apply to the category of bisexual:

John: some bisexuals are aware of the way in which gender diversity problematises the category of bisexual...I am careful to say I am attracted to more than one gender. We need strategically to use 'bisexual' as it's known - I am uncomfortable with pansexual and omnisexual. Bisexual is sufficient to freak people out, if we go further, it is even more alienating than with bisexuality.

Interviewer: You don't see 'bisexual' as binaried?

John: No - I am uncomfortable about the 'bi' aspect and the 'sexuality' aspect - I want an equivalent to 'lesbian or 'gay [in which lifestyle and political aspects are acknowledged]

Inteviewer: What are the implications of this for third or intersex people?

John: There's an option of being monosexual - you could only be attracted to one type...l think sexual identity comes from gender identity, and if you identify as male or female you can slot into gay and lesbian categories, it's much easier (2003 research, UK)

3.18 Overlap of categories can occur when people move through a number of different spaces or identities. For example contributor Kate More said 'The only space I don't occupy, I think, is bisexual. And yet, in every way taking gay, lesbian, straight, whatever into consideration. Taking all three roles, that would make me bisexual I suppose'. This kind of statement problematises assumptions underpinning mainstream forms of sexual orientation category, where a single sexual identity that is taken over a period of or years is assumed. It may mean that, as Dozier (2005) found in interviews with trans men, that participants focus less on the sex of their partner, and more on the gender organisation of the relationship.

3.19 Overall, sex/gender and sexual orientation binaries are disrupted by transgender and intersex in a number of ways in both India and the UK. The binary-based categories of female and male, lesbian, gay, heterosexual and bisexual cannot therefore be seen as discrete, or as the only forms of categorisation that are possible. Intersex is perhaps the most profoundly disruptive identity (Monro 2000a, 2005a, b). It 
provokes a questioning of the sex/gender binary system on two levels - physical, as the various conditions subsumed under the umbrella term of intersex involve physiological characteristics (for example chromosomal, hormonal and gonadal) which are other than (or a mixture of) those conventionally associated with males and females; and identity, as research contributions showed that in some cases intersex people wish to have an identity that is other, or in addition to, male or female. Non-gendered, 'third space' (see Nataf 1996), multiply gendered (sometimes called 'gender pluralist'), androgynous or multigendered people may also destabilise the discrete gender binaried system.

\title{
Trans/gender theory: Setting the scene
}

4.1 Discussions regarding the literature concerning sex and gender variance requires contextualisation with regard to the Indian situation, where, as Vanita and Kidwai (2000) note, there is a long tradition of philosophical enquiry into gender variance. Sex and gender are questioned in Buddhist, Hindu and Jain traditions, and:

\begin{abstract}
'The philosophical basis of this questioning closely resembles the deconstruction of gender in our own times by such thinkers as Monique Wittig and Judith Butler. What these thinkers would call the social construction of gender that only appears to be "natural", ancient Indian philosophers would call "illusion" that only appears to be "real"' (Vanita and Kidwai, 2000:23).
\end{abstract}

4.2 Current discussions about gender categorisation and sexuality are also echoed by some Indian theorists, for example Vanita and Kidwai (2000) note that 'There is a direct connection between the nonreality of gender and the nonabsoluteness of heterosexuality. If the two categories, "man" and "woman" are not ultimate categoies but are merely created by society to foster certain social roles and uphold institutions such as marriage, parenthood and patrilineal inheritance, then the heterosexual relation ceases to be the most important one' (2000: 23). Importantly, Vanita and Kidwai note that the notion of reincarnation renders categorisation, including sex/gender and species categorisation, fluid and mutable.

4.3 Ekins and King (2006) provide a current overview of the state of play regarding the theorisation of trans and intersex in the West. They note the way in which pioneering books by transgender theorists such as Feinberg (1996, 1998), Bornstein $(1994,1998)$ and Wilchins (1997) 'established what was effectively a new paradigm for the conceptualisation and study of transgender phenomenon' (2006: 21). These books, and the work of other transgender and intersex authors such as Stone (1991), Prosser (1998), More and Whittle (1999), Chase (1998) and Halberstam (2002) engaged with, and informed, poststructuralist theory. Their work extended some of the insights provided by early social science engagements with trans and intersex, including the work of Garfinkel (1967) and Kessler and Mckenna (1978). Poststructuralist and interactionist accounts of trans and intersex share an ontological foundation in which both sex and gender have socially constructed components, and in some cases (Feinberg 1996, 1998; Bornstein 1994, 1998; Wilchins 1997) these authors explore trans as a means of transcending and problematising sex/gender binaries. The work of the trans activists and authors listed above has been crucial to the development of a mature understanding of trans; one that is owned by some members of the trans communities, and one which on the whole celebrates rather than stigmatises sex/gender diversity.

4.4 Another development in the field of trans studies has been the recent emergence of feminist and sociological accounts of trans and intersex that are grounded in research with trans and intersex people and that - like the work of the trans theorists mentioned above - critically engage with poststructuralism and with queer theory. These authors include Hird (2000, 2002, 2006), Roen (2001), Monro (2000a, b, 2005a, b, forthcoming), Tauchert (2002), and Hines $(2005,2006)$. The work of these authors stands in contrast to that of most of the earlier feminist work on trans, which stigmatises trans people and demonstrates an inability to deal with people who move beyond or between sex/gender and sexual orientation binaries (see for instance Raymond 1979, Jeffreys 1996, Greer 1999). This new wave of writing shows more acknowledgement of the differences within the trans and intersex populations. It complements other literature on trans, including the work of Namaste (2000), Dreger (2000) and Ekins and King (2006). It also ties in with the return to biology and to sex - as opposed to gender - which is apparent in the field of gender theory more widely. As Braidotti notes:

\footnotetext{
...the social context has changed considerably since the days when poststructuralist philosophers put 'difference' on the theoretical and political agenda. The return of biological essentialism, under the cover of genetics, molecular biology, evolutionary theories, and the despotic authority of DNA has caused both an inflation and a reification of the notion of 'difference'(2006: 4).
}

4.5 For Braidotti, this 'biological turn' provokes a need to 'reset the agenda in the direction of a radical (poststructuralist) critique' (2006: 4). However, as the work of some of the feminist and sociological authors mentioned above shows, a repudiation of biological foundationalism is not necessarily the best means of 
building radical gender theory.

\section{The new wave of feminists/sociologists and sex/gender diversity}

5.1 Hird $(2000,2002,2006)$, Tauchert $(2002)$, and Hines $(2005,2006)$ variously draw on poststructuralism in their discussions of gender diversity, and share a concern with difference and with acknowledging the lived experiences of trans and intersex people. Following, in particular, Butler (1990, 1991, 1993), they discuss sex and gender as discursively constituted ${ }^{[3]}$. I will outline some of their contributions here.

5.2 Hird (2000) discusses the way in which arguments that 'sex', as well as 'gender' is a social construction disrupts the sex/gender binary that has played such a key role in the development of thinking about sex and gender. As she says:

The sex/gender binary has circulated throughout the social sciences, providing a powerful foundation for a material account of women's oppression. 'Sex' referred to biological differences between women and men, whereas 'gender' signified the processes of femininity and masculinity in social relations (2000: 348$)$.

5.3 Hird discusses poststructuralist and other critiques of the sex/gender binary, and notes the persistence of this binary even amongst some postmodern feminists. She then discusses intersexuality and transsexuality as lived bodies which challenge the binary model of sexual difference and, also, the sex/gender dichotomy. She argues that the sex/gender binary is especially reductive for intersex people, providing analysis of the medical texts to support arguments that gender does not necessarily follow on from sex; the 'authenticity of 'sex' resides not on, nor in, the body, but rather results from a particular nexus of power, knowledge, and truth' (2000). Sexes as well as genders are mutable to a degree, whilst bodies continue to be of importance. Hird discusses the options of, firstly, a multiplicity of 'sexes/genders' and secondly, the end of 'sex/gender'. In 2002, she argues for a specifically sociological approach, because 'sociology explicitly questions the relationship between sex and gender' (2002: 578). She outlines a typology of transsexualism which hypothesies the relationships between the different theoretical perspectives to trans and their ontological basis; ('authenticity', in which sex is seen as stable/fixed, 'performativity', in which identity is seen as constructed and more malleable, and 'transgressive', in which trans is seen as radically challenging sex/gender binaries, potentially rendering them obsolete. In her later work (2006) Hird discusses the 'new materialism', outlining the biological differences amongst non-human species, noting that a number of feminist scholars have taken the biological turn. Whilst continuing to argue against biological determinism, she convincingly suggests that binaried models of sex and gender are limited, given the plethora of other alternatives. Other contributions which are relevant to the further development of trans/gender theory include Hines (2006), who explores the concept of 'difference' in relation to trans studies. She argues that 'An understanding of gender as separate from sex holds the potential for a greater diversity of masculinities and femininities and is important for a sociology of transgender that takes account of a multiplicity of gendered identities and expressions which are unfixed to the 'sexed' body' (2006: 50). Ekins and King (2006) also provide a relevant typology of transgender as follows: migrating and oscillating stories (moving between genders); negating (degendering), and transcending (transgressing and moving beyond sex/gender binaries).

\section{Transmuting gender binaries: Towards a conceptual framework}

6.1 Overall, it can be argued that Western concepts of poststructuralism provides important tools for understanding sex/gender diversity (Monro 2001a, b, 2005a, b), set within the Western context rather than that of the faith-based philosophies which covered similar ground millennia earlier. Notions such as the discursive construction of subjectivity are important for unpicking way in which people are normatively conditioned into binaried sexual and gender identities. The conceptual disassociation of gender identities and bodies also allows theorisation of more complex forms of gender. However, a number of crucial problems with poststructualist theory have been raised, including a focus on performativity and transgression as opposed to the lived experiences and interests of many trans people (Hines 2006), and difficulties with the possible unintended consequences of transgression (Hird 2000). There are problems with the deconstruction of sex/gender categories as a basis of political organisation:

What is left to organise around if we don't use identities? While postmodernism has been largely unable and unwilling to apply itself to the nitty-gritty of social change, you and I don't have that luxury. We have a movement against gender oppression to mount (Wilchins 1997: 85).

6.2 In addition, poststructuralist transgender theory tends to overlook the importance of the body (Monro 2000a, b, 2005a, b). Research by authors such as Zhou et al (1995) provides evidence for biological factors to sex/gender identity. Another issue is that some transgender and other people experience themselves as 
having an essential self, or gender identity, that is 'other' than their body or social conditioning (Monro 2000a, b). Whilst this may, ultimately, also be constructed, denial of people's lived experience can be oppressive. A further problem with poststructuralism is that deconstruction can be dangerous if an ethical basis is not developed to shape this in progressive, non harmful ways (see Weeks 1995).

6.3 Given the difficulties with poststructuralism, there is a need to develop sex/gender theory which provides fully acknowledgement of the body and, where relevant to individuals, the essential self. Sex/gender theory is required that addresses identity politics, whilst avoiding co-option of trans and intersex identities into transgressive praxis. Contributions in this direction have been made by Hird $(2000,2002)$ and Ekins and King (2006). It is possible to push gender theory forward by drawing on Indian notions of sex/gender as "illusion", notions of the disembodied, liminal soul, sex/gender categories as mutable and sex/gender variance as part of the spectrum of human experience/learning (see Vanita and Kidwai 2000). The rest of this paper develops theory based on my earlier work plus the contributions of these authors. The approaches presented below form ideal types and they may in practice overlap. After outlining these approaches I will indicate a conceptual framework based on this typology. It is important to point out that some authors conceptualise gender as being determined by processes concerning sexual orientation, others see sexuality as resulting from gender, whilst still others see gender and sexuality as being interwoven, so that our gender identities are shaped by our sexual orientation and vice versa (see Richardson 2000). Whilst holding ultimately to the latter viewpoint, I focus this discussion on sex/ gender.

\section{[i] The Expansion of Male and Female Categories}

6.4 As Halberstam (2002) suggests, the elasticity of sex/gender binary categories allows sex/gender diversity to be subsumed into 'male' and 'female' - at least to an extent. Expanding sex/gender binary categories involves theorising femininities and masculinities as diverse, including people who have bodies or social roles that are different to those traditionally associated with women and men, for example, intersex people living as male or female (see Dreger 2000). The expansion of binary categories is conceptually related to notions drawn from masculinity studies. The notion of masculinities as plural involves moving away from an understanding of masculinity as white, middle class, heterosexual and able-bodied, towards thinking about masculinities as multiple, and the notion of some masculinities as hegemonic, whilst others are subordinated (see Hearn and Morgan 1990: 11). Hearn and Collinson discuss 'distinctions between gay, nonheirarchic heterosexual, and hierarchic heterosexual; between white and black, between nonfathers and fathers; unpaid careers, paid careers, and non-careers; and non-violent, violent, and militant masculinities (1994: 107). This understanding of femininities and masculinities as plural is helpful in theorising sex/gender and sexual diversity, because it includes people such as camp gay men, butch women, and trans people who have undergone full sex reassignment. It is a pragmatic strategy for the majority of the population, enabling many people with diverse sexualities and sexes/genders to gain social rights and acceptance.

6.5 There are limitations to the 'expanded sex/gender binaries' model, which can be illustrated by looking at the Indian situation. As described above, third sex/gender Hijra identities have been documented in India for over 4000 years, and these are not accountable for within the 'expanded male/female categories' model. Some Kothi identities may also fit poorly into such a model. In the West, there are also difficulties with the 'expanded bianries' model. For instance, Halberstam (2002) describes a range of female masculinities, for example tomboys, butch dykes, and masculine heterosexual women. This interpretation of sex/gender risks cooption of what can be seen as transgressive and positive identities that are arguably female, not male (for example butch). In addition, if masculinity is de-essentialised and delinked from male bodies, it becomes slippery and hard to characterise, relying on ideas that reinvoke social inequalities, such as rationality and aggression. Another problem with the expanded binaries model is that it fails to include those people who fall more fully outside of the sex/gender binary system, and perhaps defuses the potential for sex/gender pluralism because some alternative identities are subsumed into 'male' and 'female'.

\section{[ii] Moving Beyond Gender}

6.6 Feminist authors such as Lorber $(1994,2000,2003)$ argue for the 'degendering' of society. For Lorber, the division of people into two unequally valued categories underpins gender inequality. Lorber (2000) argues for moving towards a non-gendered social order, based on equality, without gender categorisation. She argues that undoing gender has to be the ultimate feminist goal (2003). Her notion of degendering is different to the gender negation discussed by Ekins and King, where people negate certain aspects of their gender identity at certain times (for example in the context of being a 'sissy boy'). It can be conceptually linked with the notion of gender liminality and also of the gender transcendence discussed by Ekins and King (2006). 
6.7 Trans authors such as Stone (1991), Bornstein (1994) and Cameron (1996) describe transsexuality as a place outside of duality. Notions of moving beyond gender, and gender liminality, are useful for conceptualising gender diversity. With regard to Indian notions of sex/gender, the concept of a soul that has successive incarnations, perhaps in bodies with different sexes, implies a liminality at the times when the soul is without a sexed body. And, as I have described above, there is an element of degendering in some Hijra discourses, where Hijras are seen as occupying a particular place in Indian society because they are outside of male or female categorisation systems. Non-categorisation and liminality are also pertinent to the sexual activity taking place in India - and in the UK - which is unclassified and undefined. Degendering is also relevant in the UK. A number of contributors to the 1996-8 research in the UK discussed the need for a less heavily gendered society - for example, the use of 'male' and 'female' on forms when sex/gender is irrelevant to the matter at hand. In a society where there is less concern with gender, androgynous and gender ambiguous people would face less barriers to social inclusion, and gender norms overall would be less heavily enforced. A certain amount of degendering is clearly helpful in achieving a more equal, inclusive society.

6.8 There are, however, some difficulties with 'degendering' approaches. Firstly, once fluidity is named, it becomes a space which people can inhabit (see Prosser 1998), and is therefore arguably no longer a non category. Secondly, identity categories seem to be necessary as a basis for cultural and political organisation (see above). If a strategy focused on erasing gender is pursued, the minority gender groups, such as Hijras, Kothis, and androgynes, - and those who have less power, including non trans women - are likely to be disadvantaged because the default dominance of men and non transgender people will remain unchallenged. Thirdly, there are some characteristics (such as childbearing and parturition) which at present are mostly only experienced by female bodied people and which have significant social implications regarding employment and welfare policies - these would erased if degendering became widespread. It may be possible to degender to an extent, but what about certain sex differences? Furthermore, as Hird argues, "it is difficult to imagine, let alone practice, subjectivities without 'gender' or 'sex'" (2000:359). Lastly, degendering, if pursued in a prescriptive manner, would deny people the choice to identify in a sexed and gendered way. As contributors to the research argued:

\title{
Abolishing gender is preposterous, as it goes against people's rights for self determination (BiCon conference 2003)
}

\begin{abstract}
There is no way to get rid of gender - it's like saying "let's turn the world into an anarchy". People are brought up in capitalism, so people will be selfish...anyone wanting to get rid of the gender system is selfish - they should let people have their fun, so long as it doesn't stop me doing what I want to do' (BiCon conference 2003)
\end{abstract}

6.9 Arguably, in isolation, degendering is an inadequate approach, in particular because it erases minority genders and overlooks the power of existing systems of categorisation and the related structural inequalities. Faced with a universalist gender vacuum, existing hegemonic norms are likely to re-emerge.

\section{[iii] Sex/gender Pluralism}

6.10 A further theoretical strategy concerns conceptualising sex/gender as plural, and as a spectrum, a field, or intersecting spectra or continua. Sex and gender are seen as being more finely grained than is the case with the binary system, and as being formed via the interplay of different characteristics associated with sex/gender and sexuality. Sex/gender pluralism involves 'calls for new and self-conscious affirmations of different gender taxonomies' (Halberstam 2002: 360). It involves conceptualising gender as 'fields' or 'groupings' of - in some cases overlapping - masculinities, femininities, and gender diverse identities, and sex as a continuum. It could entail the more widespread use of pronouns such as 'ze' and 'hir' (see Feinberg 1996) for people who chose them as alternatives to male/female pronouns. More sex/gender possibilities also means acknowledging that the categories of 'lesbian', 'gay', bisexual' and 'heterosexual' cannot encompass all sexual orientation options, and complementary terms are likely to become more widespread.

6.11 Gender pluralism is quite clearly the most relevant conceptual approach for cultures which already have third or other sexes and genders, such as that found in India. Kothi and Hijra identities fit easily within the sex/gender pluralist model, and the concept of reincarnation is extremely compatible with notions of sex/gender pluralism - it includes those who incarnate in a variety of sexes/genders at different times. There was also support for sex/gender pluralism amongst some of the UK research contributors, some of whom discussed the way that they would prefer to identify as something other than female or male if this was socially possible. For instance, sex and gender as a continuum or as a spectrum was discussed by contributor Ann Goodley, who said: 
us, are programmed to only see in black and white, in monochrome. A concept I actually see as a rainbow, or many shades of grey, I prefer to see it as a rainbow, that's more positive, the grey areas are actually the technicolor colours between black and white. I believe that there are elements of all the colours in everybody, but that people knee-jerk into one column or the other quite often in Western patriarchal society. And I think that's damaging.

Interviewer: I'd like to ask a bit further into that if that's OK

Ann: Surely

Interviewer: Um, it sounds as if you're saying that it's not a rigidly gendered binary system?

Ann: No I'm certain this division isn't on behavioural, biological or spiritual levels, if there is such a thing, but on all levels. In terms of personal identity it's one of the ways in which each of us defines ourselves and is defined by other people that forms a portion of a very complex mosaic that makes a person

6.12 Some of the Western literature supports the spectrum model of sex and gender. Rothblatt (1995) discusses what she terms 'gender continuum theory', a shift away from bipolar sex/gender categories towards a multiplicity of genders. The notion of a gender and sex continuum may be expanded. For example one (non trans) bisexual contributor described genders as places in space rather than a continuum. Recent participant observation (2006) in the UK bisexual and fetish communities indicates that notions of multiple genders and pan gender are gaining currency within the subcultures associated with these communities in a way that was not evidence in the 1990s. However, debates about the viability and advisability of a plural gender system will continue. One trans contributor to the 2003 UK research said that the time was not right for a UK movement for third and other sexed/gendered people's rights, given existing social conservatism and bigotry and the need to fight other battles first, whilst another said: 'third gender $-I$ resist that phrase, because all it does is rigidify, codify stuff' (James Green). A further contributor argued that 'it's [third gender] got a sort of dustbin sense to it, even though I know people would use it for themselves' (Hamish). Gender pluralism could therefore be seen to perpetuate categorisation. As Hird says,

...confronted with analysis of heteronormativity, marginalization in lesbian and gay communities, and the general fragmentation of identities, multiplying sexes/genders seems to offer a way to express a variety of sexed and gendered identities without anyone actually having to give up their 'chosen' identity (2000: 359)

6.13 Despite these difficulties, there are arguments in support of pluralist gender theory. Politically, the development/recognition of identities that are intersex, androgynous, third and other sex, or gender diverse in other ways is powerful because it enables calls for justice and social change. It moves beyond the poststructuralist deconstruction of gender and sexuality binaries towards reconstruction - potentially towards a more diverse and tolerant society. Theoretically, gender pluralism allows for the inclusion of both essentialist and constructionist approaches to gender and sexuality - and it moves gender theory beyond the binary system and cultural relativism.

\section{Analysis and conclusion}

7.1 This paper has outlined some of the ways in which sex/gender diversity in India and the UK challenges sex/gender/sexual orientation binaries. It has provided a review of relevant recent developments in the literature. I have mapped out different ways of thinking about gender diversity in a typology consisting of expanding gender binaries, moving beyond gender, and gender pluralism. This last section of the paper aims to explore some of the theoretical implications of this typology.

7.2 The ways in which sex/gender categories are constructed, and the means by which they are conceptualised, have developed over the last ten years. In the UK, there is now more space for sex/gender diversity and notions concerning sex/gender pluralism have purchase in certain sexual subcultures; in India there has been a growth of interest in Western sexual orientation categories and in lesbian/gay rights in conjunction with the rights of gender-diverse people, but this is heavily striated by locality and socioeconomic position. The three models of sex/gender outlined above are all currently in evidence both in the West and in the country that I have chosen for a cross-cultural comparison (India). However, certain subject positions are erased by the different types. The 'expanding genders' model erases some physiologically intersex people, and people who do not identify as male or female. The 'degendering' model erases people who identify strongly with - or are forced to identify strongly with - a particular gender, and 'sex/gender pluralism' erases those people who do not identify with gender at all (although arguably degendering could also form a category amongst gender pluralists). It is important to point out that some people move 
between 'expanded genders', 'degendering', and/or 'gender pluralism'. 'Migrating' and 'oscillating' form major categories in Ekins' and King's (2006) sex/gender typology, and Wilson (2002) shows using empirical material on transgender that people often move from a liminal and multiple stage of gender identification to one in which gender is singular, socially recognised, and stable. There may also be some purchase in the concepts of 'fuzziness' (Tauchert 2002) concerning sex/gender - people may not belong strictly to one category or another. Braidotti's argument that 'We live in permanent processes of transition, hybridization, and nomadization' (2006:2) continues to have relevence. However, the different types form a means of beginning to conceptualise sex/gender variance. They can be related to the systems developed by other authors, notably Ekins and King's (2006) latter categories of degendering and transgression (which for these authors incorporates sex/gender pluralism).

7.3 What are the broader implications of sex/gender diversity for gender theory? The conceptual framework that seems to be emerging draws on the work of, in particular, Vanita and Kidwai (2000), Hird (2000, 2002, $2006)^{[4]}$ and Ekins and King (2006), as well as my earlier publications $(2000,2004,2005 a, b$, forthcoming) is as follows: Sex, gender, and sexual orientation are all constructed and mutable (via agency or otherwise) to a degree, and they are interrelated in complex and dynamic ways. People may experience characteristics such as gender as fixed, although ultimately they are mutable (even if only through processes of aging, death, and reincarnation if this is seen as valid). Different sexed and gendered levels form spectra (for ease of conceptualisation, spectra running between female and male) which combine and interact in ways that are unique to each individual. These spectra are present on different levels: genetic, endocrinological, gonadal, secondary sexual characteristics, core identity/identities (which can include spiritual identity/identities and political beliefs), social identity/identities, and sexual identity or identities ${ }^{[5]}$. The spectra are structured by physiological, psychological, social, cultural, and other factors (including economic) in a variety of ways. The spectra are cross-cut by a range of other social structuring factors centred around ethnicity, nationality, geographical location, socio-economic class, ability, familial structure, political and/or faith factors, and other physical and cultural factors. Sex and gender are formed in relation to these other factors, and related discourses such as homophobia, which in some cases heavily sanction certain forms of sex/gender expression (see Monro 2005a, 2006).

7.4 The conceptual framework I have outlined could be criticised for being a neo-liberal pluralist (see Braidotti 2006). It is individualist in the sense that it accounts for individual diversity and agency, but it does also foreground social structuring factors. I argue that whilst it is a pluralist model, it is a model that could be used to further radical change concerning sex/gender/sexual orientation if used in a way that supports diversity and challenges inequality. Overall, subjects are transgressive or conformist depending on their social positioning and the 'fit' between this and their sex/gender characteristics. Individuals strategically position themselves and may be more or less conformist or transgressive at any one time. Therefore, whilst Western notions of queering are relevant - in that 'queer itself...works to destabilise divisive regimes based on binaristic thinking and perception' (Cranny-Francis et al 2003), the model is not a queer one per se - it is a model that integrates queer and mainstream understandings of gender. Whilst further work concerning queer sociology and trans (see Hines 2006) would be useful, the diversity present amongst Hijra, Kothi, trans and intersex people means that imposing notions of queerness onto the trans and intersex population would be colonising, as well as ethnocentric. Arguably, what is important is whether trans. Hijra, Kothi and intersex people are included in an equal way in social theory and society, and whether gender theory is expanded sufficiently to support greater diversity concerning sex and gender in India as well as within the West.

\section{Notes}

${ }^{1}$ The term 'sex/gender' is used here to emphasise the interrelated nature of these social characteristics as well as their mutability.

${ }^{2}$ A discussion of these theories in relation to trans and intersex is provided by Monro (2005a).

${ }^{3}$ See for example Monro (2005a) for a more detailed discussion.

${ }^{4}$ I do not deal here with Hird's 2002 typology of transsexualism as authentic, performative, or transgressive.

${ }^{5}$ These are not ordered hierarchically.

\section{Acknowledgements}

The author would like to acknowledge and thank the ESRC, who funded the original research, the research 


\section{References}

BLACKBURN, M. (2002) Sexuality and Disability. Oxford: Butterman-Heinneman.

BLACKBURN, M.V. (2005) 'Agency in Borderland Discourses: Examining language use in a community centre with Black queer youth', Teacher's College Record, 107(1): 89-113.

BOELLSTORFF, T. (2004) 'Playing Back the Nation: Indonesian transvestites', Cultural Anthropology, 19: 159.

BORNSTEIN, K. (1994) Gender Outlaw: On men, women and the rest of us. New York, London: Routledge Publications.

BORNSTEIN, K. (1998) My Gender Workbook. New York: Routledge Publications.

BRAIDOTTI, R. (2006) Metamorphosis: Towards and materialist theory of becoming, Cambridge: Polity Press.

BUTLER, J. (1990) Gender Trouble: Feminism and the Subversion of Identity. New York, Routledge Publications.

BUTLER, J. (1991) 'Imitation and Gender Insubordination', in: D. Fuss (ed) Inside/Out. London, New York: Routledge Publications.

BUTLER, J. (1993) Bodies That Matter: On the Discursive Limits of "Sex". New York: Routledge Publications.

CHASE, C. (1998) 'Affronting Reason', pp. 205-219 in: D. Atkins (ed) Looking Queer: Body Image and Identity in Lesbian, Bisexual, Gay and Transgender Communities. New York, London: Harrington Park Press.

CAMERON, L. (1996) Body Alchemy: Transsexual Portraits. USA: San Francisco: Cleis Press.

CHAKRABORTY, T. (2002) 'Patna Eunuchs in Power Play', Telegraph, 6.3.2002.

CRANNY-FRANCIS, A., WARING, W., STAVROPOULOS, P., AND KIRKBY, J. (2003) gender Studies: Terms and debates, Houndmills, Basingstoke: Palgrave MacMillan.

DOZIER, R. (2005) 'Beards, Breasts and Bodies: Doing gender in a gendered world', Gender and Society, 19(3): 297-316.

DREGER, A.D. (ed) (2000) Intersex in the Age of Ethics. Maryland: University Publishing Group.

EKINS, R. AND KING, D. (2006) The Transgender Phenomenon, London, Thousand Oaks, New Delhi: Sage Publications.

FEINBERG, L. (1996) Transgender Warriors: Making History from Joan of Arc to Dennis Rodman. Boston: Beacon Press.

FEINBERG (1998) Transliberation: Beyond pink or blue'. Boston, MA: Beacon Press.

FIRESTONE, S. (1970) The Dialectic of Sex. New York: Bantam Books.

GARFINKEL, H. (1967) Studies in Ethnomethodology, Englehall Cliffs, NJ: Prentice Hall.

GREER, G. (1999) The Whole Woman. New York: Alfred A. Knopf.

GUPTA, A. (2002) 'Transgender Law and Civil Rights', From the Lawyers Collective, Mumbai.

HALBERSTAM, J. (2002) 'An Introduction to Female Masculinity: Masculinity without men', pp. 355-374 in: R. Adams and D. Savran (eds) The Masculinity Studies Reader, Malden, Massachusetts and Oxford: Blackwell Publishers.

HEARN, J. and COLLINSON, D.L. (1994) 'Theorizing Unities and Differences Between Men and Between Masculinities' pp. 97-118 in H. Brod and M. Kaufman (1994) (eds) Theorizing Masculinities. London: Sage. 
HEARN, J, and MORGAN, D. (1990) Men, Masculinities and Social Theory. London: Unwin Hyman.

HEARN, J, and MORGAN, D. (2006) 'What's The Difference? Bringing particularity to Queer studies of transgender', Journal of Gender Studies , 15(1): 49-66.

HERDT, G. (ed) (1994) Third Sex Third Gender: Beyond Sexual Dimorphism in Culture and History. New York: Zone Books.

HINES, S. (2006) 'What's The Difference? Bringing Particularity to Queer Studies of Transgender', Journal of Gender Studies, 15(1): 49-66.

HINES (2005) '"I am a Feminist but..." Transgender Men, Women and Feminism in: J. Reger (ed) Different Wavelengths: Studies of the Contemporary Women's Movement', London, New York: Routledge.

HIRD, M.J. (2006) 'Animal Trans', Australian Feminist Studies, 21(49): 35-48.

HIRD, M.J. (2002) 'For a Sociology of Transsexualism' Sociology, 36(3): 577-595.

HIRD, M.J. (2000) 'Gender's Nature: Intersexuals, Transsexuals and the "Sex"/"Gender" Binary' Feminist Theory, 2000, 1(3): 347-364.

JEFFREYS, S. (1996) 'Heterosexuality and the Desire for Gender' in: D. Richardson (ed) Theorising Heterosexuality: Telling it Straight. (Buckingham, Philadelphia: Open University Press).

KESSLER, S. AND MCKENNA, W. (1978) Gender: An Ethnomethodological approach, Chicago: University of Chicago Press.

KIRSCH, , M.H. (2000) Queer Theory and Social Change. London and New York, Routledge.

LORBER, J. (1994) Paradoxes of Gender. Newhaven, London: Yale University Press.

LORBER, J. (2000) 'Using Gender to Undo Gender: A Feminist degendering movement', Feminist Theory 1(1): 79-95.

LORBER, J. (2003) 'Undoing Gender: Degendering and Feminist Theory and politics', Southern Sociological Society, 2003.

MASEQUESMAY, G. (2003) 'Negotiating Multiple Identities in a Vietnamese Support Group', Journal of Homosexuality, 45(2-4): 193-215.

MONRO, S. (forthcoming) 'Transgender: Destabilising Feminisms?' in: V. Munro, C. Stychin: Sexuality and the Law. Feminist Engagements, Glasshouse Press.

MONRO, S. (2006) 'Transgender Youth: Stories of an Excluded Population', in: C. Leccardi and E. Ruspini (eds) A New Youth. Aldershot: Ashgate Publishing, 298 -320.

MONRO, S. (2005a) Gender Politics: Activism, Citizenship and Sexual Diversity. London: Pluto Press.

MONRO, S. (2005b) 'Beyond Male and Female: Poststructuralism and the Spectrum of Gender', International Journal of Transgenderism, 8(1): 3-22.

MONRO, S. (2000a) Transgender Politics. Unpublished thesis: Sheffield, University of Sheffield.

MONRO, S. (2000b) Theorizing Transgender Diversity: Towards a Social Model of Health,' Sexual and Relationship Therapy, 15(1): 33-45.

MORE, K., and WHITTLE, S. (1999) (eds) Reclaiming Genders: Transsexual grammars at the fin de siecle. London: Cassell.

NAMASTE (2000) Invisible Lives: The erasure of transsexual and transgendered people. Chicago: University of Chicago Press.

NATAF, Z. (1996) Lesbians Talk Transgender. London: Scarlett Press. PENROSE, W. (2001) 'Hidden in History: Female homoeroticism and women of a "third nature" in the South Asian past', Journal of the History of Sexuality, Vol 10, No. 1: 3-39.

PROSSER, J. (1998) Second Skins: The Body Narratives of Transsexuality. USA: Columbia University Press. 
PUCL-K (2003) Human Rights Violations against the Transgender Community: A Study of Kothi and Hijra Sex Workers in Bangalore, India. Bangalore: People's Union for Civil Liberties, Karnataka.

QUEEN, C. and SCHIMEL, L. (1997) (eds) Pomosexuals: Challenging assumptions about gender and sexuality. San Francisco: Cleis Press.

RAYMOND, J. (1980) The Transsexual Empire: The Making of the She-Male. (London: The Women's Press).

RAYMOND, J. (1994) 'The Politics of Transgender', Feminism and Psychology 4(4): pp. 628-633.

RICHARDSON, D. (2000) Rethinking Sexuality. London: Sage.

ROEN, K. (2001) 'Transgender Theory and Embodiment: The risk of racial marginalisation', Journal of Gender Studies, 10(3): 253-263.

ROTHBLATT, M. (1995) The Apartheid of Sex: A Manifesto for the Freedom of Gender. USA: Crown Publishers.

SEABROOK, J. (1997) 'Not "straight”, not gay'. The Pioneer, 30.9.1997.

STONE, S. (1991) 'The Empire Strikes Back: A post-transsexual manifesto', in: D. Epstein and K. Straub (editors) Body Guards: The cultural politics of gender ambiguity'. London: Routlege Publications.

TAUCHERT, A. (2002) 'Fuzzy Gender: Inbetween male and female embodiment and intersex', Journal of Gender Studies 11(1): 29-38.

VANITA, R AND KIDWAI, S (2000) 'Introduction' pp. 1-46 in: Vanita, R. and Kidwai, S. Same-Sex Love in India: Readings from Literature and History', Houndmills, Basingstoke: Macmillan.

WEEKS, J. (1995) Invented Moralities: Sexual Values in an Age of Uncertainty. Cambridge: Polity Press.

WILCHINS, R. (1997) Read My Lips: Sexual subversion and the end of gender'. Ithaca, New York: Firebrand Books.

WILSON, M. (2002) 'I am the Princess of Pain, for I am the Princess in the Brain: Liminal transgender identities, narratives, and the elimination of ambiguities', Sexualities, 5(4): 425-448.

ZHOU, J., HOFMAN, M., GOOREN, L. and SWAAB, D. (1995) 'A Sex Difference in the Human Brain and its Relation to Transsexuality', Nature 378: pp. 68-70. 